\title{
A Nonparametric Formula Relating the Elasticity of a Factor Demand to the Elasticity of Substitution*
}

\author{
James Feigenbaum \\ Utah State University, Logan, UT, USA \\ Email: j.feigen@aggiemail.usu.edu
}

How to cite this paper: Feigenbaum, J. (2019) A Nonparametric Formula Relating the Elasticity of a Factor Demand to the Elasticity of Substitution. Theoretical Economics Letters, 9, 240-246. https://doi.org/10.4236/tel.2019.91019

Received: January 17, 2019

Accepted: February 17, 2019

Published: February 20, 2019

Copyright $\odot 2019$ by author(s) and Scientific Research Publishing Inc. This work is licensed under the Creative Commons Attribution International License (CC BY 4.0).

http://creativecommons.org/licenses/by/4.0/

\begin{abstract}
It is well known for a Cobb-Douglas production function that the elasticity of a factor demand is the inverse of the share of output going to the other factors. Since Cobb-Douglas has a unit elasticity of substitution, the demand elasticity trivially equals the ratio of the elasticity of substitution to the share of output going to the other factor. I show here that this result can be generalized to any constant returns to scale production function. As a result, if a factor is known to be a substitute for (complement of) other factors, the inverse of the share of output going to other factors will be a lower (upper) bound for the factor's elasticity of demand.
\end{abstract}

\section{Keywords}

Elasticity of Substitution, Elasticity of Labor Demand, Output Share

\section{Introduction}

Between 1984 and 2017, real median household income in the United States increased by $0.6 \%$ per year ${ }^{1}$. During the same period, real per capita GDP increased by $1.6 \%$ per year ${ }^{2}$. Much has been written about the deficit between these two income growth rates. One possible culprit for the stagnation of most workers' wages that gets considerable attention, albeit mostly from laypeople and politicians, is excessive immigration, especially illegal immigration. Of course, economists understand that the degree to which an influx of workers will de-

${ }^{*}$ I would like to thank Scott Findley, Martin Gervais, Pedro Silos, and Josh Smith for their comments and advice.

${ }^{1}$ https://fred.stlouisfed.org/series/MEHOINUSA672N

${ }^{2}$ https://fred.stlouisfed.org/series/GDPCA and https://fred.stlouisfed.org/series/B230RC0A052NBEA 
press wages depends on the elasticity of demand for labor, but estimating supply and demand functions is a difficult econometric exercise, which muddies the policy debate. Here I derive a simple nonparametric formula that expresses the elasticity of demand for a factor in terms of variables that are observable or, at least, boundable.

The elasticity of demand will equal the elasticity of substitution between the factor and any other factors divided by the share of output going to those other factors. To derive this we need only assume that the production function exhibits constant returns to scale and that factor markets are perfectly competitive. It is not surprising that the elasticity of demand for a good should depend on the elasticity of substitution between the good and its alternatives, though it is remarkable that the two elasticities are exactly proportional. However, the formula is also consistent with the common textbook intuition that the demand for a good becomes less elastic as you define it more narrowly. It is already well known that the demand for a factor will become perfectly elastic if the factor is the sole input in production since the marginal product must be constant if there are constant returns to scale. What is not so obvious is that the elasticity of demand decreases monotonically with the share of output going to the factor, converging to the elasticity of substitution in the limit where the factor's contribution to output is vanishingly small.

Like the elasticity of demand, the elasticity of substitution can be difficult to measure. But if there is high confidence that two factors are substitutes (or complements), we can bound the elasticity of their demands. Returning to the example of wages for low-skilled workers, most evidence suggests that low-skilled labor is a substitute for more technologically sophisticated factors ${ }^{3}$. Assuming that the relevant elasticity of substitution is greater than 1 , this will be a lower bound on the elasticity of demand for low-skilled labor. Thus, a $1 \%$ increase in the supply of low-skilled labor can, at most, cause a $1 \%$ decrease in low-skilled wages. The flow of immigrants into America's labor force has simply not been large enough to explain a $40 \%$ deficiency in median wages, compounded over three decades.

While there has been considerable research that seeks to elucidate the role that the elasticity of substitution between final goods plays in the determination of consumer demand functions for those final goods, to my knowledge this is the first general result linking the elasticity of substitution between factors and the demand for those factors. As Blackorby and Russell [2] demonstrate, corresponding results for consumer demand functions are much more complicated than what I find here regarding factor demands. This is likely a consequence of the fact that income and substitution effects both arise in a consumer demand problem whereas there is no analog to income effects when a firm decides how much of each factor to employ.

The paper proceeds as follows. In Section I, we review the familiar example of ${ }^{3}$ See, for example, Acemoglu and Restrepo [1]. 
a Cobb-Douglas production function and demonstrate that the formula is trivially satisfied in this special case. In Section II, we derive the formula for a general production function with two factors and constant returns to scale. In Section III, we show how a production function with more than two factors can effectively be reduced to one with two factors, preserving the utility of the formula. We conclude in Section IV with a discussion of how the formula applies to labor markets.

\section{Cobb-Douglas Production}

Suppose we just have two inputs $Z_{1}$ and $Z_{2}$ with factor prices $p_{1}$ and $p_{2}$, and the production function is $H\left(Z_{1}, Z_{2}\right)$. If factor markets are competitive, in equilibrium each factor price must equal the corresponding marginal product:

$$
p_{i}=H_{i}\left(Z_{1}, Z_{2}\right)
$$

To begin with, let us review the familiar case of a Cobb-Douglas production function

$$
H\left(Z_{1}, Z_{2}\right)=Z_{1}^{\alpha} Z_{2}^{1-\alpha},
$$

where $\alpha \in[0,1]$. The marginal products will be

$$
p_{1}=\alpha\left(\frac{Z_{1}}{Z_{2}}\right)^{\alpha-1}
$$

and

$$
p_{2}=(1-\alpha)\left(\frac{Z_{1}}{Z_{2}}\right)^{\alpha} \text {. }
$$

Thus, the ratio of the factor prices will be

$$
\frac{p_{1}}{p_{2}}=\frac{\alpha}{1-\alpha} \frac{Z_{2}}{Z_{1}},
$$

and the elasticity of substitution is

$$
\xi=\frac{\partial \ln \left(\frac{Z_{2}}{Z_{1}}\right)}{\partial \ln \left(\frac{p_{1}}{p_{2}}\right)}=1 .
$$

Note also that (2) and (3) imply that the share of output going to the first factor is

$$
\frac{p_{1} Z_{1}}{H\left(Z_{1}, Z_{2}\right)}=\frac{\alpha Z_{1}^{\alpha} Z_{2}^{1-\alpha}}{Z_{1}^{\alpha} Z_{2}^{1-\alpha}}=\alpha .
$$

From (4), we see that the elasticity of demand for the second factor is

$$
\frac{\partial \ln \left(Z_{2}\right)}{\partial \ln \left(p_{2}\right)}=-\frac{1}{\alpha}=-\left(\frac{p_{1} Z_{1}}{H\left(Z_{1}, Z_{2}\right)}\right)^{-1} .
$$




\section{Elasticity of Factor Demand for a General Production Function with Two Factors}

Now let us generalize to the case of any constant returns to scale production function $H$. Because $H$ has constant returns to scale, we can rewrite it as

$$
H\left(Z_{1}, Z_{2}\right)=Z_{2} h(z) \text {, }
$$

where

$$
h(z)=H(z, 1)
$$

is the intrinsic production function and

$$
z=\frac{Z_{1}}{Z_{2}}
$$

is the ratio of the two factors. Then the marginal product of $Z_{1}$ reduces to just the derivative of $h$ :

$$
\frac{\partial}{\partial Z_{1}}\left(Z_{2} h\left(\frac{Z_{1}}{Z_{2}}\right)\right)=Z_{2} h^{\prime}\left(\frac{Z_{1}}{Z_{2}}\right) \frac{1}{Z_{2}}=h^{\prime}(z) .
$$

Likewise, the marginal product of $Z_{2}$ is

$$
\frac{\partial}{\partial Z_{2}}\left(Z_{2} h\left(\frac{Z_{1}}{Z_{2}}\right)\right)=h\left(\frac{Z_{1}}{Z_{2}}\right)+Z_{2} h^{\prime}\left(\frac{Z_{1}}{Z_{2}}\right)\left(\frac{-Z_{1}}{Z_{2}^{2}}\right)=h(z)-z h^{\prime}(z)
$$

Thus, we can express the factor prices as functions of $z$,

$$
\begin{gathered}
p_{1}=h^{\prime}(z) \\
p_{2}=h(z)-z h^{\prime}(z),
\end{gathered}
$$

and the ratio of the factor prices is

$$
\frac{p_{2}}{p_{1}}=\frac{h(z)}{h^{\prime}(z)}-z
$$

The derivative of this ratio with respect to $z$ is

$$
\frac{\partial}{\partial z}\left(\frac{p_{2}}{p_{1}}\right)=\frac{h^{\prime}(z)}{h^{\prime}(z)}-\frac{h(z) h^{\prime \prime}(z)}{\left(h^{\prime}(z)\right)^{2}}-1=-\frac{h(z) h^{\prime \prime}(z)}{\left(h^{\prime}(z)\right)^{2}} .
$$

Let $\xi(z)$ denote the elasticity of substitution between the two factors. Then

$$
\xi(z)^{-1}=\frac{\partial \ln \left(\frac{p_{2}}{p_{1}}\right)}{\partial \ln z}=-\frac{h(z) h^{\prime \prime}(z)}{\left(h^{\prime}(z)\right)^{2}} \frac{z}{\frac{h(z)}{h^{\prime}(z)}-z}=-\frac{z h^{\prime \prime}(z)}{h^{\prime}(z)} \frac{h(z)}{h(z)-z h^{\prime}(z)}
$$

Let us denote the share of output going to $Z_{1}$ by

$$
\alpha(z)=\frac{p_{1} Z_{1}}{H\left(Z_{1}, Z_{2}\right)}=\frac{Z_{1} h^{\prime}(z)}{Z_{2} h(z)}=\frac{z h^{\prime}(z)}{h(z)} .
$$

Our question is how factor prices vary with the supply of the corresponding factor. The response of $p_{2}$ to a change in $Z_{2}$ is 


$$
\frac{\partial p_{2}}{\partial Z_{2}}=\frac{\partial}{\partial Z_{2}}\left(h\left(\frac{Z_{1}}{Z_{2}}\right)-\frac{Z_{1}}{Z_{2}} h^{\prime}\left(\frac{Z_{1}}{Z_{2}}\right)\right) .
$$

This simplifies to

$$
\frac{\partial p_{2}}{\partial Z_{2}}=h^{\prime}(z)\left(-\frac{Z_{1}}{Z_{2}^{2}}\right)+\frac{Z_{1}}{Z_{2}^{2}} h^{\prime}(z)-z h^{\prime \prime}(z)\left(-\frac{Z_{1}}{Z_{2}^{2}}\right)=\frac{z^{2}}{Z_{2}} h^{\prime \prime}(z) .
$$

Thus, the elasticity of $p_{2}$ with respect to $Z_{2}$ is

$$
\frac{\partial \ln \left(p_{2}\right)}{\partial \ln \left(Z_{2}\right)}=\frac{Z_{2}}{p_{2}} \frac{\partial p_{2}}{\partial Z_{2}}=\frac{Z_{2}}{h(z)-z h^{\prime}(z)}\left(\frac{z^{2}}{Z_{2}} h^{\prime \prime}(z)\right)=\frac{z^{2} h^{\prime \prime}(z)}{h(z)-z h^{\prime}(z)} .
$$

We can rewrite this as

$$
\frac{\partial \ln \left(p_{2}\right)}{\partial \ln \left(Z_{2}\right)}=-\left(-\frac{z h^{\prime \prime}(z)}{h^{\prime}(z)} \frac{h(z)}{h(z)-h^{\prime}(z) z}\right) \frac{z h^{\prime}(z)}{h(z)} .
$$

Using (18) and (19), we get that the elasticity is

$$
\frac{\partial \ln \left(p_{2}\right)}{\partial \ln \left(Z_{2}\right)}=-\frac{\alpha(z)}{\xi(z)}
$$

The elasticity of the price of the second factor with respect to the supply of the second factor is the output share of the first factor divided by the elasticity of substitution between the two factors. Alternatively, the elasticity of demand for $Z_{2}$ is

$$
\frac{\partial \ln \left(Z_{2}\right)}{\partial \ln \left(p_{2}\right)}=-\frac{\xi(z)}{\alpha(z)}
$$

\section{Generalizing to Three or More Factors}

Now suppose that we have a constant returns to scale production function $F$ of $n+1$ factors, where $n \geq 2$. Let us denote these factors $X_{1}, \cdots, X_{n}$, and $Z_{2}$ and the corresponding factor prices by $q_{1}, \cdots, q_{n}$, and $p_{2}$. We can still make use of the result from Section 3 by constructing a composite factor equal to the total expenditure on the inputs $X_{1}, \cdots, X_{n}$ :

$$
Z_{1}=\sum_{i=1}^{n} q_{i} X_{i} .
$$

Let us define the effective production function ${ }^{4}$

$$
H\left(Z_{1}, Z_{2}\right)=\max _{X_{1}, \cdots, X_{n}} F\left(X_{1}, \cdots, X_{n}, Z_{2}\right)
$$

subject to (26).

Proposition: $H$ will exhibit constant returns to scale.

Proof: Let $\lambda>0$. Then

${ }^{4}$ For the common special case in which $F\left(X_{1}, \cdots, X_{n}, Z_{2}\right)=\tilde{H}\left(G\left(X_{1}, \cdots, X_{n}\right), Z_{2}\right)$, where both $\tilde{H}$ and $G$ exhibit constant returns to scale, we will have $H=\tilde{H}$ and $Z_{1}=G\left(X_{1}, \cdots, X_{n}\right)$. In particular, if $\tilde{H}$ is a constant elasticity of substitution production function, then the elasticity of substitution $\xi$ that we obtain by using $H$ will be the same as what we would obtain from $\tilde{H}$. 


$$
H\left(\lambda Z_{1}, \lambda Z_{2}\right)=\max _{X_{1}, \cdots, X_{n}} F\left(X_{1}, \cdots, X_{n}, \lambda Z_{2}\right)
$$

subject to

$$
\sum_{i=1}^{n} q_{i} X_{i}=\lambda Z_{1}
$$

Thus,

$$
H\left(\lambda Z_{1}, \lambda Z_{2}\right)=\max _{X_{1}, \cdots, X_{n}} \lambda F\left(\frac{X_{1}}{\lambda}, \cdots, \frac{X_{n}}{\lambda}, Z_{2}\right)
$$

subject to

$$
\sum_{i=1}^{n} q_{i} \frac{X_{i}}{\lambda}=Z_{1}
$$

Let us define $x_{i}=\frac{X_{i}}{\lambda}$. Then,

$$
H\left(\lambda Z_{1}, \lambda Z_{2}\right)=\max _{x_{1}, \cdots, x_{n}} \lambda F\left(x_{1}, \cdots, x_{n}, Z_{2}\right)
$$

subject to

$$
\sum_{i=1}^{n} q_{i} x_{i}=Z_{1}
$$

But the $X_{i}$ and $X_{i}$ are just dummy variables, so

$$
H\left(\lambda Z_{1}, \lambda Z_{2}\right)=\lambda H\left(Z_{1}, Z_{2}\right)
$$

Since the price of $Z_{1}$ is by construction 1, the elasticity of demand for $Z_{2}$ will be, from Section 3,

$$
\frac{\partial \ln Z_{2}}{\partial p_{2}}=\frac{H\left(Z_{1}, Z_{2}\right)}{Z_{1}} \xi\left(Z_{1}, Z_{2}\right),
$$

where $\xi\left(Z_{1}, Z_{2}\right)$ is the elasticity of substitution between $Z_{2}$ and the composite factor $Z_{1}$.

\section{An Application to Labor Markets}

As an example of how this formula can be useful, consider a macroeconomic model in which capital and labor are the factors of production, but labor can be differentiated into multiple types ${ }^{5}$. If factor markets are competitive, the elasticity of demand for labor type $Z_{2}$ will depend on both the share of output going to all of the other labor types, i.e. $Z_{1} / H\left(Z_{1}, Z_{2}\right)$ in (32), and the elasticity of substitution between this labor type and the composite of all the other factors, i.e. $\xi\left(Z_{1}, Z_{2}\right)$.

The simplest nontrivial case has two skill levels of labor. For example, Krussel et al. [3] employ a specification exhibiting capital-skill complementarity, where capital and high-skilled labor, which will correspond to our $X_{1}$ and $X_{2}$, have a constant elasticity of substitution less than 1 . Meanwhile, the combination $Z_{1}$ of high-skilled labor and capital has a constant elasticity of substitution with ${ }^{5}$ We could also differentiate capital. 
low-skilled labor $Z_{2}$ that is greater than 1. For this special case, it is easily shown that (32) applies.

Now we know that we can generalize this result to any constant returns to scale production function. As long as low-skilled labor is a substitute for high-skilled labor and/or capital, the elasticity of substitution $\xi$ is greater than one; we can infer that the elasticity of demand for low-skilled labor will be bounded from below (in absolute value) by the inverse of the output share of high-skilled labor and capital. That in turn is bounded from below by one. Inversely, the wage elasticity of demand for low-skilled labor will be bounded from above (in absolute value) by one. Thus, a $1 \%$ increase in the supply of low-skilled labor can at most cause a $1 \%$ decrease in low-skilled wages.

This is roughly consistent with Borjas' [4] estimate of the wage elasticity of demand for very low-skilled labor in Miami during the Mariel boat lift. Looking specifically at high school dropouts, he found the wage elasticity to lie between 0.5 and $1.5^{6}$. For a very narrow definition of low-skilled labor, the share of output going to other factors will essentially be 1 . Thus, the wage elasticity will just be the inverse of the elasticity of substitution between high school dropouts and other inputs. To account for a wage elasticity between 1 and 1.5 , that elasticity of substitution can be less than 1 for essential services of manual labor that presently have no convenient technological substitutes, such as janitorial services or truck driving. The boat lift also occurred in the 70s and 80s when fewer jobs had been replaced by technology, so low-skilled labor might then have been more complementary to high-skilled labor and capital.

\section{Conflicts of Interest}

The author declares no conflicts of interest regarding the publication of this paper.

\section{References}

[1] Acemoglu, D. and Restrepo, P. (2017) Robots and Jobs: Evidence from US Labor Markets. NBER Working Paper No. 23285.

[2] Blackorby, C. and Russell, R.R. (1989) Will the Real Elasticity of Substitution Please Stand Up? (A Comparison of the Allen/Uzawa and Morishima Elasticities). American Economic Review, 79, 882-888.

[3] Krusell, P., Ohanian, L.E., Ríos-Rull, J.-V. and Violante, G.L. (2000) Capital-Skill Complementarity and Inequality: A Macroeconomic Analysis. Econometrica, 68, 1029-1053. https://doi.org/10.1111/1468-0262.00150

[4] Borjas, G.J. (2017) The Wage Impact of the Marielitos. A Reappraisal. Industrial and Labor Relations Review, 70, 1077-1110. https://doi.org/10.1177/0019793917692945

[5] Clemens, M.A. and Hunt, J. (2017) The Labor Market Effects of Refugee Waves: Reconciling Conflicting Results. NBER Working Paper No. 23433.

${ }^{6}$ Clemens and Hunt [5] argue that Borjas' [4] estimates are biased upward, which would bring the wage elasticity even more into line with the nonparametric formula. 